\title{
Who Are Our Students?: A Synthesis of Foreign and Second Language Research on Individual Differences with Implications for Instructional Practice
}

Rebecca L. Oxford

Teachers of second or foreign languages, to be most effective, must understand who their students really are. This means teachers must comprehend differences among their students in many individual characteristics, such as age, sex, motivation, anxiety, selfesteem, tolerance of ambiguity, risktaking, cooperation, competition, and language learning strategies and styles.
This article synthesizes previous and current research on these individual differences among students and provides implications for instructional practice. Researchers, teachers, and administrators should heed the article's message: we need to have keys for knowing our students better, and here are some of the most significant keys available.

Optimal instruction of a second or foreign language requires teachers to understand important learning-related differences in their students: age, sex, motivation, anxiety, self-esteem, tolerance of ambiguity, risk-taking, cooperation, competition, and language learning strategies and styles. This article synthesizes research on these individual differences among students and provides instructional implications. These student characteristics are the focus here because they have received the greatest amount of research attention and because they seem to be very important to the language learning process. Although many other factors might be discussed, such as physical dexterity or aural acuity, those factors are not currently at the heart of language learning research. For additional commentaries on individual differences in language learning, see Galbraith and Gardner (1988) and Skehan (1989).

Before presenting student characteristics, it is important to mention two caveats. First, simple cause-and-effect relationships are rare in language learning. For instance, tolerance of ambiguity and risk-taking do not, by themselves, always create consistent results for all language learners; these factors interact in a complex way with other factors-such as anxiety, self-esteem, motivation, and learning styles-to produce certain effects in language learning. Models of language learning are therefore highly complicated and multifactored. Second, many of the student characteristics mentioned here are difficult to measure; examples are risk-taking ability and 
self-esteem. Therefore, research on such student features is often exploratory and a little speculative. Even with these two caveats, we can use our common sense to understand and use existing research results. Unless we look at current findings, however imperfect they might be, we stand the chance of failing to know our students closely and therefore of failing to provide instruction that fully meets their learning needs.

For each student characteristic, we will present research findings immediately followed by instructional implications. We will start first with age.

\section{AGE}

Age is often mentioned as an influence on language learning success (Scarcella \& Oxford, 1992). Oxford (1982), based on Genesee (1978), cites the two main arguments in favor of learning foreign or second languages at younger ages: (1) the cognitivenativist argument that language learning is an innate ability that dissipates with age (Chomsky, 1972) and (2) the neurological argument that one's neural plasticity decreases with age, thus affecting language learning ability (Lenneberg, 1967). There are also several opposite arguments, focused on the fact that in some instances older learners attain higher levels of foreign or second language acquisition than their younger counterparts (Ervin-Tripp, 1974; Fathman, 1975; Burstall, 1974). Advantages for different ages have been variously attributed to: (1) prior experience in language learning, (2) onset of formal operations (i.e., abstract thinking abilities), (3) cognitive maturity, (4) kind of input, (5) affective factors, (6) sociocultural factors, and (7) one or more sensitive or critical periods (Oxford, 1982).

To resolve these differences, Krashen, Long, and Scarcella (1979, 1981) and Scarcella and Oxford (1991) argue that older learners have an advantage in terms of rate of acquisition of syntax and morphology, but that ultimate fluency and nativelike pronunciation in a new language are clearly better among those who start learning it as children. Adults proceed more rapidly through the initial stages of syntactic and morphological development than children but not the later stages, and they often experience fossilization, that is, the permanent cessation of second or foreign language development (Selinker, 1972).

These results suggest that age differences in language learning performance are expectable. Teachers might consider making students aware of these age differences for the purpose of planning 
realistic learning goals. However, age differences should not be an excuse for teachers to artificially limit the challenges presented to students (Scarcella \& Oxford, 1992).

\section{SEX}

Sex has received scant research attention in research on the development of second and foreign language skills. This is surprising, considering all the research on sex differences in other areas, including native language development and use (see, e.g., Maccoby \& Jacklin, 1974; Bardwick, 1971; Tannen, 1990). The rare research on sex differences in second or foreign languages has concentrated on how people learn these languages, that is, on the choice of strategies they employ for language learning. Politzer (1983) reported that in learning a new language females used social strategies significantly more often than males. Oxford, Nyikos, and Ehrman (1988) and Oxford (1989) summarized Politzer's study and several others touching on sex differences in language learning. These investigators conclude that in typical language learning situations women use significantly more learning strategies than men and use them more often; but after strategy training, men and women show roughly equivalent, though different, strategy strengths.

Sex differences in the use of language learning strategies are intriguing, but we need to know more before we can establish firm instructional implications on the basis of such gender research. While investigators are gathering more data, teachers might pay more attention to cultural differences in sex roles as related to students' language learning performance (Oxford, Nyikos, \& Ehrman, 1988).

\section{MOTIVATION}

Motivation decides the extent of active, personal engagement in learning, yet researchers do not understand exactly how motivation works in language learning. One reason for lack of clarity on the operation of language learning motivation is that most researchers have not bothered to define "motivation" adequately. To redress this problem, let us adopt the following definition of motivation (based on Crookes \& Schmidt, 1989; Maehr \& Archer, 1987; Keller,1983).

Motivation is composed of four internal, attitudinal factors and three external, behavioral characteristics. The internal factors 
include: interest, relevance, expectancy, and outcomes. Interest in the subject or process is based on the learner's existing attitudes, experience, and background knowledge. Relevance involves the perception that personal needs such as achievement, affiliation with other people, and power are being met. Expectancy relates to the belief that the learner's involvement will be either a success or a failure. Outcomes are the intrinsic or extrinsic rewards felt by the learner while learning. The behavioral features of motivation are: decision, persistence, and activity level. The learner decides to choose, pay attention to, and engage in one activity but not others; persists over an extended time and returns to the activity after any interruptions; and maintains a high activity level.

Clearly, attitudes directly affect behaviors within this motivational framework. A language teacher who overcorrects the student can lower the expectation of success and destroy the reward, thus reducing the student's willingness to pay attention or persist in learning the language.

If language activities are perceived as irrelevant or uninteresting, or if they conflict with the learner's particular style, the learner might tune out or lower the level of involvement.

High motivation might spur learners to interact with native speakers of the language (Schumann, 1986), which in turn increases the amount of input learners receive (Scarcella \& Oxford, 1992; Krashen, 1982). Motivation often leads learners to use a variety of learning strategies that can facilitate greater skill in language learning (Oxford \& Nyikos,1989). Motivation encourages greater overall effort on the part of language learners and typically results in greater success in terms of general language proficiency (see, e.g., Clement, Major, Gardner, \& Smythe, 1977; Gardner, 1985). Motivation is also related to increased competence in specific language skills such as listening, reading, and speaking (Tucker, Hamayan, \& Genesee, 1976; Genesee, 1978). Strong motivation helps learners maintain their language skills after classroom instruction is over (Gardner, Lalonde, Moorcroft, \& Evers, 1985; Oxford \& Crookall, 1988).

Most major researchers have chosen a social-psychological orientation toward language learning motivation. Gardner, a leading social-psychological theorist (see, e.g., Gardner 1985; Gardner, Lalonde, Moorcroft, \& Evers, 1985; Gardner \& Lambert, 1959, 1972), has championed integrative motivation - the desire to learn a language to integrate oneself with the target culture-as preferable to instrumental motivation - the desire to learn the language in order to get a better job or meet a language requirement. According to 
this formulation, if a student wants to become close to native speakers of the target language, the student will learn the language more effectively than if his or her goal is simply to get a better job based on target language skills. The desire to become integrated with the target culture relates strongly to the social-psychological construct known as Speech Accommodation Theory (Giles \& Byrne, 1982; Beebe, 1988), in which the learner's degree of identification with the "in-group" (the group that speaks the target language and is therefore advantaged socially and communicatively) is a crucial factor in language success. Schumann's Acculturation Model (1978, 1986) likewise concerns many aspects of integrative motivation, though the model uses other terms.

Many researchers including Oller (1981), Au (1988), Horwitz (1990), and Crookes and Schmidt (1989) disagree with the primacy of integrative motivation (called by many terms, such as acculturation or in-group identification) in language learning. These theorists contend that one particular kind of motivation might not be uniformly superior in terms of ultimate language learning performance. For instance, Horwitz (1990) pointed to research showing that instrumental motivation was more predictive than integrative motivation for language learning success in the Philippines, while integrative motivation was a stronger influence than instrumental motivation in English-speaking Canadian populations.

Instructional implications founded on motivation research are fairly clear. Teachers can do many things to heighten language learning motivation. For instance, teachers can make sure the material and the tasks are communicative, nonthreatening, exciting, relevant, appropriately challenging, capable of stimulating successful performance, and presented according to students' favored learning styles (Oxford, 1990a, 1990b; Ely, 1986b). Moreover, teachers can help reverse any negative attitudes (including stereotypes) that might harm student motivation. Ralph (1989) offers a number of helpful suggestions for enhancing language learners' motivation.

\section{ANXIETY}

Anxiety is "a state of apprehension, a vague fear" (Scovel, 1978, p.134). Such apprehension or fear can cause motivation to plummet and attitudes to turn negative. Low motivation can then lead to poorer performance, which then results in still greater anxiety. Anxiety sometimes arises in response to a particular situation or event (situational or state anxiety), but occasionally it is a 
permanent character trait, as in a person who is predisposed to be fearful of many things (trait anxiety). The kind of anxiety seen in the language classroom is usually situational or state anxiety rather than trait anxiety. A recent book (Horwitz \& Young, 1991) is completely devoted to situational anxiety in the language classroom.

Some experts believe that anxiety can be helpful rather than harmful. The "good" kind of anxiety, called "facilitating anxiety," can be useful in keeping students alert (Scovel, 1978; Brown, 1987). The "bad" kind of anxiety is known as "debilitating anxiety," because it harms learners' performance in many ways, both indirectly through worry and self-doubt and directly by reducing participation and creating overt avoidance of the language. "Facilitating anxiety" is only helpful for very simple learning tasks, but not with more complicated processes such as language learning (Horwitz, 1990). By implication, there might be no such thing as facilitating anxiety for language learners, though a bit of positive tension might be $O K$.

Many kinds of language activities can generate performance anxiety, depending on the student. Speaking in front of others (oral reports, skits, role-play, etc.) is often the most anxiety-provoking of all, according to Horwitz and Young (1991). Students prone to anxiety when speaking include introverts who do not enjoy interacting with others or who dislike performing in front of others, or visual learners who learn better with visual referents. Yet speaking is not the only skill that triggers anxiety. For some students, writing or listening can also create fear, depending on the students' learning style preferences and skill level. Even reading, which has the advantage of a permanent, written stimulus to which students can return repeatedly, can be anxiety- provoking-especially to individuals who have difficulty reading efficiently or well in their native language due to a learning disability or lack of appropriate reading strategies.

The classroom structure can be a source of anxiety. Littlewood (1981) presents a graphic description of anxiety in the traditional classroom, which is powerfully teacher-centered at the expense of student-student communication. Students fear they will receive the teacher's negative criticism in front of the whole class and will thus appear stupid, so they feel anxious. Conversely, a highly open, fluid, communicative classroom structure can heighten anxiety for students who want detailed, structured tasks that do not require interpersonal communication (Oxford, Ehrman, \& Lavine, 1991).

Anxiety can come from a fear of, or from the actual experience of, "losing oneself" in the target culture. This occurs especially in culture shock, "a form of anxiety that results from the loss of 
commonly perceived and understood signs and symbols of social intercourse" (Adler, 1987, p. 25). Language learners who are living in the target culture frequently experience culture shock, at least initially. Culture shock involves some or all of these symptoms: emotional regression, panic, anger, self-pity, indecision, sadness, alienation, "reduced personality," and physical illness. Anxiety can also occur when students have low motivation-when the language learning process is forced, annoying, irrelevant, style-conflicting, or generally unsuccessful.

Teachers can diagnose anxiety through a number of instruments, the best known of which is the "Foreign Language Classroom Anxiety Scale" by Horwitz (1990). In addition, anxiety is often readily observable. Lavine and Oxford (1990) offer likely signs of anxiety: forgetting, being careless, coming late or unprepared, squirming, playing with hair or clothing, nervously touching objects, stuttering or stammering, complaining about unexplained aches and pains, withdrawing from conversation, avoiding eye contact, showing hostility, smiling or nodding with exaggeration, or being excessively competitive or compliant.

By becoming aware of potential signs of anxiety, teachers can take a major step toward improving the classroom climate. It is important to keep in mind, however, that certain behaviors that flag anxiety in one culture might simply be normal behavior in other cultures (see Hofstede, 1986). After diagnosing anxious behavior, teachers must act to reduce anxiety, depending on students' needs and cultural background. This action can include: (1) avoidance of overcorrection, sarcasm, and intimidation; (2) fair testing and rewards; (3) addressing students' learning styles; (4) development of positive self-talk (self-encouragement) and cognitive "reframing" of negative or irrational ideas; (5) cooperative learning; (6) use of dialog journals, diaries, emotional checklists, and anxiety graphs to track feelings; (7) behavioral contracting, including setting realistic goals; (8) relaxation techniques such as music, deep breathing, and humor; and (9) establishment of student support groups (see Lavine \& Oxford, 1990; Horwitz, 1990).

\section{SELF ESTEEM}

Self-esteem is a self-judgment of worth or value, based on feelings of "efficacy," a sense of interacting effectively with one's own environment (White, 1959). Efficacy implies that some degree of control exists within oneself. If a person's "locus of control"-the place one attributes control of one's life-is totally external (e.g., 
fate, luck, chance, the government, God, the Devil) as opposed to at least partially internal (Rotter,1966), then self-esteem often becomes a problem.

Just like anxiety, self-esteem can be a trait (an inherent personality characteristic) or a state (related to a particular situation). Global self-esteem arises when the person is at a mental age of eight. It is based on two factors: (1) self-perceptions of competence in various broad areas, such as academics, athletics, social interaction, physical appearance, and conduct, and (2) a personal assessment of the importance of each of these areas. Global self-esteem can suffer if the student does not do well in an area that he or she considers very significant. Performance often improves when the learner makes a globally positive self-assessment, though this assessment might be inaccurate.

Situational self-esteem is much more specific. It relates to a specific situation, event, or activity type. A person can feel good about himself or herself globally or generally yet at the same time experience low self-esteem in a particular situation or environment (Oxford, 1990b; Scarcella \& Oxford, 1992). Not surprisingly, unsuccessful language learners - those who have particular problems in the language learning situation-have lower self-esteem than successful language learners. Whether this affects their overall self-esteem or only their situational self-esteem partly depends on how important language learning is to the individuals involved.

Research suggests that teachers might consider encouraging students to develop their self-esteem in the language classroom. Helping students assess their progress realistically and positively is very important to self-esteem (Oxford, 1990b; Moskowitz, 1978). Teachers can also aid students in discounting, when feasible, the perceived importance of those areas in which they do not perform well (Harter, 1986).

\section{TOLERANCE OF AMBIGUITY AND RISK TAKING ABILITY}

Tolerance of ambiguity is the acceptance of confusing situations. As noted by Ely (1989), "second language learning is fraught with uncertainty" about meanings, referents, and pronunciation, so a degree of ambiguity tolerance is essential for language learners. Students who are able to tolerate moderate levels of confusion are likely to persist longer in language learning than students who are overly frightened by the ambiguities inherent in learning a new language (Chapelle, 1983; Naiman, Frohlich, Stern \& Todesco, 1978). Too much tolerance of ambiguity might lead to unquestion- 
ing acceptance and cognitive passivity.

Students who do not need immediate "closure," i.e., who can deal with some degree of ambiguity, often appear to use better (more communicatively-oriented) language learning strategies than students who require rapid closure (Oxford \& Ehrman, 1989; Ehrman \& Oxford, 1989). Likewise, Ely (1989) discovered that the degree of ambiguity tolerance significantly predicted students' choice of many (although not all) learning strategies.

Students who fear the frequent ambiguities of language learning often suffer reduced risk-taking ability. Research suggests that it is more useful for language learners to take moderate but intelligent risks, such as guessing meanings based on background knowledge and speaking up despite the possibility of making occasional mistakes, rather than taking no risks at all or taking extreme, uninformed risks (Oxford, 1990a, 1990b; Brown, 1987).

Language students who fear ambiguity or whose self-esteem is low frequently "freeze up," allowing their inhibitions to take over completely (Beebe, 1983; Stevick, 1976). Decreases in risk-taking frequently occur when students feel extreme discomfort in the language classroom (Ely, 1986a). Students who avoid risks are stalled by actual or anticipated criticism from others or by self-criticism that they themselves supply. When they do not have enough practice, their language development becomes seriously stunted.

Tolerance of ambiguity and risk-taking ability, though sometimes considered inherent character traits, can be developed through a nonthreatening classroom climate, class discussion of fears, individual counseling with inhibited students, and training in strategies that facilitate taking risks (e.g., compensation strategies like guessing or using synonyms). Teachers can help learners relax and not be worried if they do not understand everything right away; and at the same time, they have the ability to assist learners in knowing when and how to take risks, particularly in conversational settings. See Oxford (1990b) for more details.

\section{COOPERATION AND COMPETITION}

Still another aspect of the learner that is significant in language learning is cooperation vs. competition. Cooperating with others is crucial, and overly strong competition can often block progress. Cooperation comes in many forms, including working in tandem with the teacher, with fellow students, and with native speakers of the language who are not connected with the classroom situation. 
Cooperating with peers in the classroom is a special instance of cooperation. It involves a cooperative task structure, in which group or team participants work together on aspects of the same task, and sometimes a cooperative reward structure, in which participants receive a common reward for their efforts. Cooperative learning groups foster a sense of "positive interdependence" and mutual support (Slavin, 1983; Kagan, 1986; Kohn, 1986, 1987).

In language learning, cooperation has the following benefits: stronger motivation, greater achievement, increased satisfaction for teachers and students, more language practice, more feedback about language errors, and greater use of varied language functions (Bejarano, 1987; Gunderson \& Johnson, 1980; Bassano \& Christison, 1988; Wong Fillmore, 1985; Gaies, 1985; Seliger, 1983). Cooperation drives many recent language teaching methods and approaches, such as Community Language Learning and the Natural Approach. Additional advantages of cooperation in general educational research include higher self-esteem and confidence, decreased prejudice, and increased altruism and respect for others (Oxford, 1990b).

But cooperation is not always second nature to language learners, especially in the ESL setting. Reid (1987) found that ESL students typically do not choose to work in cooperative groups and do not know about the benefits of cooperative learning. Their native cultures sometimes fail to provide extended experiences of students working together on common projects or goals.

Extreme competition in the language classroom-not the common competition of team play or individual gamesmanship but instead a more exaggerated form of competition-is related to severe anxiety, inadequacy, guilt, hostility, withdrawal, and fear of failure. See Bailey's (1983) review of diary studies for reflections of these emotions among highly competitive language learners.

Research recommends that teachers help reduce any dysfunctional competition and encourage cooperation in the language classroom. Cooperation enhances communicativeness. A variety of specific cooperative learning structures, such as Think-Pair-Share, Numbered Heads Together, and Jigsaw, can respect the needs of extroverts and introverts and enable all students to take part in communicative language development. These formats have been used widely and researched extensively with significant success (Kohn, 1986, 1987; Johnson \& Johnson, 1989; Slavin, 1981, 1983, 1990; Slavin, Sharan, Kagan, Hertz-Lazarowitz, Webb, \& Schmuck, 1985). 


\section{LANGUAGE LEARNING STRATEGIES AND STYLES}

Language learning strategies are the specific behaviors or techniques learners use to improve any aspect of their own language development (Oxford \& Nyikos, 1989). Language learning styles are the general approaches students use to learn a new language (Oxford, Lavine, \& Ehrman, 1991). Strategies and styles are intimately related.

Research suggests that effective learners use a variety of learning strategies appropriate to the nature of the task, the learning material, and the person's goals and stage of learning (see, e.g., Ehrman, 1989; Oxford, 1989; Skehan, 1989; Oxford \& Crookall, 1989). The actual number of learning strategies used might not be the key factor in whether those strategies aid language learning success; learners' own tailoring or orchestrating of the strategies might be even more important, because in some instances unsuccessful language learners use as many strategies as effective language learners (Vann \& Abraham, 1989; Lavine \& Oxford, forthcoming). For more detailed reviews of research on strategies, see O'Malley and Chamot (1990), Cohen (1990), Oxford and Crookall (1989), and Wenden and Rubin (1987).

Four major dimensions or aspects of language learning style appear to be the most important: the analytic-global aspect, sensory preferences, intuitive/random vs. sensory/sequential learning, and the orientation toward closure or openness (see Oxford, 1990a, 1991; Oxford, Lavine, \& Ehrman, 1991; Ehrman,1989; Scarcella \& Oxford, 1992). These style aspects-along with other variables mentioned above-largely determine the individual's choice of language learning strategies. In other words, language learning style is one of the key determiners of the techniques that students use to learn another language. We will illustrate this now.

One very important dimension of language learning styles is analytic vs. global. Analytic students tend to concentrate on grammatical details and often avoid more free-flowing communicative activities. They like contrastive analysis, rule-learning, and dissecting words and sentences. Analytic learners do not like to guess without adequate time to reflect; nor do they like to use compensation strategies like paraphrasing when they do not know a particular word; they would rather look up the information and have it exactly right. Such strategies often slow down overly analytic students and keep these students from obtaining sufficient conversational practice. In contrast, global students use socially interactive, communicative strategies which emphasize the main idea 
over details. They dislike grammatical minutiae, avoid analysis, and enjoy compensation strategies like guessing, paraphrasing, or using synonyms. On the other hand, their lack of concern with accuracy sometimes causes global students to fossilize early.

Another very significant stylistic difference highlights sensory preferences: visual, auditory, and hands-on (a combination of kinesthetic or movement-oriented and tactile or touch-oriented). Sensory preference refers to the physical, perceptual learning channels with which the student is the most comfortable. Visual students like to read and obtain a great deal of visual stimulation. For them, lectures, conversations, and oral directions without any visual backup can be very confusing and anxiety-producing. Auditory students, on the other hand, are comfortable without visual input and therefore enjoy lectures, conversations, and oral directions. They are excited by classroom interactions in role-plays and similar activities. They sometimes, however, have difficulty with written work. Hands-on students like lots of movement and enjoy working with tangible objects, collages, and flashcards. Sitting at a desk for very long is not comfortable for them; they prefer to have frequent breaks and move around the room. Reid (1987) demonstrated that ESL students varied significantly in their sensory preferences, with people from certain cultures differentially favoring the three different modalities for learning. Reid found that students from Asian cultures, for instance, are often highly visual, while Hispanics are frequently auditory. Many non-Western cultures value hands-on experiences, and therefore numerous students from these cultures prefer a hands-on learning style.

Another key aspect of learning style consists of intuitive/random learning vs. sensory/sequential learning. Intuitive/random students think in abstract, large- scaled, nonsequential ways and are able to distill the main principles of how the new language works and thus conceive of the underlying language system. They are often bored by concrete, step-by-step learning and would rather take daring intellectual leaps. Sensory/sequential students use strategies that focus on concrete facts in a step-by-step, organized fashion. Abstract principles and underlying language systems are not very important to sensory/sequential learners, who prefer to do the task at hand and then move on to the next activity. These learners are frequently slow and steady, progressing at their own rate but able to achieve learning goals if those goals are made very clear. Randomness and lack of consistency in lesson plans are difficult for such students to handle in the language classroom.

A final aspect of learning style is orientation to closure, or the 
degree to which the person needs to reach decisions or clarity. This dimension is very closely related to tolerance of ambiguity and to general flexibility. Students oriented toward closure are hard-working, organized, and planful and have a strong need for clarity. They want lesson directions and grammar rules to be clearly spelled out. Such students avoid spontaneous conversations and games in the language classroom-unless, of course, they have had adequate time to use metacognitive strategies, such as preparing their vocabulary lists and reviewing the rules involved in any given interaction. Students less oriented to closure are sometimes known as "open learners." They take language learning far less seriously, treating it like a game to be enjoyed rather than a set of tasks to be completed and judged. They eschew most planning and preparing strategies. Because of their relaxed attitude, open learners sometimes do better in developing fluency than do more closure-oriented learners (Ehrman \& Oxford, 1989). Keeping open to new information without forcing premature closure appears to be part of a continuous quest for meaning, according to that study. Openness can be a benefit in some situations, particularly those that require flexibility and the development of fluency, but can be a detriment in other situations, such as highly structured and traditional classroom settings.

Language learners need to make the most of their comfortable style preferences by using familiar strategies related to their styles. However, learners must also extend themselves beyond their "stylistic comfort zone" to use learning strategies that might not initially feel right. For instance, an analytic learner cannot stay stuck in memorizing and analyzing vocabulary but must push hard for a more global understanding of meaning. A global student, conversely, needs to do some analysis in order to understand the structure of the language and learn how to communicate with precision and skill.

According to the research, language teachers can assess their own learning and teaching styles and become aware of the styles of their students (most easily done through style inventories). Based on this information, teachers can provide varied, multisensory lessons that appeal to many different learning styles. They can, with patience, begin to spot style conflicts and to help learners stretch beyond their "stylistic comfort zone" to develop new language learning strategies (Oxford, 1990a, 1991; Oxford, Ehrman, \& Lavine, 1991; Ehrman, 1989). Appropriately chosen language learning strategies are highly useful to effective performance in developing a second or foreign language. Oxford (1990b) lists a number of principles for 
teaching language learning strategies: assess students' current strategies by means of a survey or interview, weave strategy training into regular classroom activities, make sure the strategies to be taught are relevant to students' needs, and be as explicit as possible about how to use strategies and how to transfer them to new situations.

\section{CONCLUSIONS}

Language teachers can benefit from knowing more about their students' characteristics. Even though the research is not as complete as it will be in future years, we can nevertheless learn from current findings as we work to provide the best possible instruction to our language students. In this article we have discussed a wide range of factors that research indicates to be important in language learning, all the way from age and sex to language learning styles and strategies. Some things teachers cannot do anything about, but others are malleable. We have shown how to use research findings to understand our students better in the quest for better language teaching.

\section{THE AUTHOR}

Rebecca Oxford is Associate Professor at the University of Alabama, where she holds a joint appointment in the MA-TESOL Program in the College of Arts and Sciences and in the Curriculum and Instruction Area in the College of Education. She has a Ph.D. from the University of North Carolina in educational psychology, a master's from Boston University in the same field, and two degrees in Russian. She is currently co-editing a 30-volume ESL series for university intensive programs (Heinle \& Heinle) and is lead author of an introductory Spanish text for university students (D.C. Heath). She publishes widely and presents internationally on psychological aspects of language learning.

\section{REFERENCES}

Adler, R.S. (1987). Culture shock and the cross-cultural learning experience. In L. F. Luce \& E. C. Smith (Eds.), Toward Internationalism: Readings in Cross-Cultural Communication, 2nd ed. New York: Newbury House, 24-35. 
Au, S.Y. (1988). A critical appraisal of Gardner's socio-psychological theory of second-language (L2) learning. Language Learning 38(1), 75-100.

Bailey, K. N. (1983). Competitiveness and anxiety in adult second language learning: Looking at and through the diary studies. In H. W. Seliger \& M.H. Long (Eds.), Classroom-Oriented Research in Second Language Acquisition. Rowley, MA: Newbury House.

Bardwick, J. (1971). Psychology of Women: A Study of Biocultural Conflicts. New York: Harper \& Row.

Bassano, S. \& Christison M. A. (1988). Cooperative learning in the ESL classroom. TESOL Newsletter 22(2), 1,8-9.

Beebe, L. M. (1983). Risk-taking and the language learner. In $\mathrm{H}$. W. Seliger \& M. H. Long (Eds.), Classroom-Oriented Research in Second Language Acquisition. Rowley, MA: Newbury House.

Beebe, L.M. (1988). Issues in Second Language Acquisition: Multiple Perspectives. New York: Newbury House / Harper \& Row.

Bejarano, Y. (1987). A cooperative small-group methodology in the language classroom. TESOL Quarterly 21(3), 483-504.

Brown, H. D. (1987). Principles of Language Learning and Teaching (2nd ed.). Englewood Cliffs, NJ: Prentice-Hall.

Burstall, C. (1974). Primary French in the Balance. Windsor, England: NFER.

Chapelle, C. A. (1983). The Relationship Between Ambiguity Tolerance and Success in Acquiring English as a Second Language in Adult Learners. University of Illinois, Urbana-Champaign, IL, unpublished doctoral dissertation.

Chomsky, N. (1972). Language and Mind. New York: Harcourt, Brace.

Clement, R., Major, L., Gardner, R. C., \& Smythe, P. C. (1977). Attitudes and motivation in second language acquisition: An investigation of Ontario francophones. Working Papers on Bilingualism 12, 1-20.

Cohen, A. D. (1990). Language Learning: Insights for Learners, Teachers, and Researchers. New York: Newbury House/Harper \& Row.

Crookes, G., \& Schmidt, R. (1989). Motivation: Reopening the research agenda. University of Hawaii Working Papers in ESL $8(1), 217-256$.

Ehrman, M. E. (1989). Ants and grasshoppers, badgers and butterflies: Quantitative and qualitative investigation of adult language learning styles and strategies. Union Institute, Cincinnati, $\mathrm{OH}$, unpublished doctoral dissertation. 
Ehrman, M. E. \& Oxford, R. L. (1989). Effects of sex differences, career choice, and psychological type on adults' language learning strategies. Modern Language Journal 73(1), 1-13.

Ely, C. (1986a). An analysis of discomfort, risktaking, sociability, and motivation in the L2 classroom. Language Learning 36(1), $1-25$.

Ely, C. (1986b). Language learning motivation: A descriptive and causal analysis. Modern Language Journal 70(1), 28-35.

Ely, C. (1989). Tolerance of ambiguity and use of second language learning strategies. Modern Language Journal 22(5), 437-445.

Ervin-Tripp, S. (1974). Is second language learning like the first? TESOL Quarterly (8), 111-127.

Fathman, A. (1975). The relationship between age and second language production ability. Language Learning 25, 245-253.

Foss, K. A., \& Reitzel, A. C. (1988). A relational model for managing second language anxiety. TESOL Quarterly 22(3), 437-454.

Gaies, S. J. (1985). Peer Involvement in Language Learning. New York: Harcourt Brace Jovanovich.

Galbraith, V. \& Gardner, R. C. (1988). Individual Difference Correlates of Second-Language Achievement: An Annotated Bibliography. London: University of Western Ontario.

Gardner, R. C. (1985). Social Psychology and Second Language Learning: The Role of Attitudes and Motivation. London: Edward Arnold.

Gardner, R. C. \& Lambert, W. E. (1959). Motivational variables in second language acquisition. Canadian Journal of Psychology 13, 266-272.

Gardner, R. C. \& Lambert, W. E. (1972). Attitudes and Motivation in Second Language Learning. Rowley, MA: Newbury House.

Gardner, R. C., Lalonde, R. H., Moorcroft, R., \& Evers F. T. (1985). Second Language Attrition: The Role of Motivation and Use. London: University of Western Ontario.

Genesee, F. (1978). Is there an optimal age for starting second language instruction? McGill University, Montreal, unpublished ms.

Giles, H., \& Byrne, J. L. (1982). An intergroup approach to second language acquisition. Journal of Multicultural and Multilingual Development 3, 7-40.

Gunderson, B. \& Johnson, D. (1980). Building positive attitudes by using cooperative learning groups. Foreign Language Annals 13(1), 39-43. 
Harter, S. (1986). Feeling good about yourself isn't enough. Today $8(2), 2-3$.

Hofstede, G. (1986). Cultural differences in teaching and learning. International Journal of Intercultural Relations 10, 301-320.

Horwitz, E. (1990). Attending to the affective domain in the foreign language classroom. In S. S. Magnan (ed). Shifting the Instructional Focus to the Learner. Middlebury, VT: Northeast Conference on the Teaching of Foreign Languages, 15-33.

Horwitz, E. K. \& Young, D. J. (1991). Language Learning Anxiety. Englewood Cliffs, NJ: Prentice-Hall.

Johnson, D. W. \& Johnson, R. (1989). Cooperation and Competition: Theory and Research. Edina, MN: Interaction Book Co.

Johnson, D. W., Johnson R., \& Holubec, E. (eds.) (1986). Circles of Learning: Cooperation in the Classroom (rev. ed.). Edina, MN: Interaction Book Co.

Kagan, S. (1986). Cooperative learning and sociocultural factors in schooling. In Beyond Language: Social and Cultural Factors in Schooling Language Minority Students. Bilingual Education Office, California State Department of Education, Sacramento, CA, 231-290.

Keller, J. M. (1983). Motivational design of instruction. In C.M. Reigeluth (ed), Instructional Design, Theories, and Models. Hillsdale, NJ: Erlbaum, 289-320.

Kohn, A. (1986). No Contest: The Case Against Competition. Boston, MA: Houghton Mifflin.

Kohn, A. (1987). It's hard to get out of a pair-Profile: . David and Roger Johnson. Psychology Today, Oct., 53-57.

Krashen, S., Long, M. \& Scarcella, R. (1979). Age, rate, and eventual attainment in second language acquisition. TESOL Quarterly 13, 573-582.

Krashen, S., Long, M. \& Scarcella, R. (1981). Child-Adult Differences in Second Language Acquisition. Rowley, MA: Newbury House.

Lavine, R. Z. \& Oxford, R. L. (1990). Addressing affective issues in the second and foreign language classroom. Paper presented at the annual meeting of the Modern Language Association, Chicago.

Lavine, R. Z. \& Oxford, R. L. (forthcoming). Language learning diaries: Let the learners tell us. Submitted for publication.

Lenneberg, E. (1967). Biological Foundations of Language. New York: Wiley. 
Littlewood, W. (1981). Communicative Language Teaching: An Introduction. Cambridge: Cambridge University Press.

Maccoby, E. E. \& Jacklin C. N. (1974). The Psychology of Sex Differences. Stanford, CA: Stanford University Press.

Maehr, M. L. \& Archer, J. (1987). Motivation and school achievement. In L. G. Katz (ed). Current Topics in Early Childhood Education. Norwood, NJ: Ablex, 85-107.

McCombs, B. L. (1987). The role of affective variables in autonomous learning. Paper presented at the annual meeting of the American Educational Research Association, Washington, DC.

Moskowitz, G. (1978). Caring and Sharing in the Foreign Language Classroom. Rowley, MA: Newbury House.

Naiman, N., Frohlich, M., Stern, H. H. \& Todesco A. (1978). The Good Language Learner. Research in Education Series 7. Ontario Institute for Studies in Eduction, Toronto.

Oller, J. W. (1981). Research on the measurement of affective variables: Some remaining questions. In R.W. Anderson (ed). New Dimensions in Second Language Acquisition Research. Rowley, MA: Newbury House, 114-127.

O'Malley, J. M. \& Chamot, A. U. (1990). Learning Strategies in Second Language Acquisition. Cambridge: Cambridge University Press.

Oxford, R. (1982). Research on language loss: A review with implications for foreign language teaching. Modern Language Journal 66, 160-169.

Oxford, R. (1989). Use of language learning strategies: A synthesis of studies with implications for strategy training. System $17(2), 235-247$.

Oxford, R. (1990a). Language learning strategies and beyond: A look at strategies in the context of styles. In S. S. Magnan (ed), Shifting the Instructional Focus to the Learner. Middlebury, VT: Northeast Conference on the Teaching of Foreign Languages, $35-55$.

Oxford, R. (1990b). Language Learning Strategies: What Every Teacher Should Know. New York: Newbury House/Harper \& Row.

Oxford, R. (1991). Language learning styles. SCOLT Newsletter Spring, 2-3.

Oxford, R. \& Crookall, D. (1988). Language learning strategies. In J. Berko-Gleason (ed), You CAN Take It With You: Helping Students Maintain Second Language Skills. Englewood Cliffs, NJ: Prentice-Hall, 23-49. 
Oxford, R. \& Crookall, D. (1989). Language learning strategies: Methods, findings, and instructional implications. Modern Language Journal 73, 404-419.

Oxford, R. \& Ehrman, M. (1989). Psychological type and adult language learning strategies: A pilot study. Journal of Psychological Type 16, 22-32.

Oxford, R., Ehrman, M., \& Lavine, R. Z. (1991). Style wars: Teacher-student style conflicts in the language classroom. In S. S. Magnan (ed), Challenges in the 1990s for College Foreign Language Programs. Boston, MA: Heinle and Heinle, 1-25.

Oxford, R. \& Nyikos, M. (1989). Variables affecting choice of language learning strategies by university students. Modern Language Journal 73(3), 291-300.

Oxford, R., Nyikos, M., \& Ehrman, M. (1988). Vive la difference? Reflections on sex differences in use of language learning strategies. Foreign Language Annals 21(4), 321-329.

Politzer, R. L. (1983). An exploratory study of self-reported language learning behaviors and their relation to achievement. Studies in Second Language Acquisition 6, 54-68.

Ralph, E. G. (1989). Research on effective teaching: How can it help L2 teachers motivate the unmotivated learner? Canadian Modern Language Review 46(1), 135-146.

Reid, J. M. (1987). The learning style preferences of ESL students. TESOL Quarterly 21, 87-111.

Rotter, J.B. (1966). Generalized expectancies for internal vs. external control of reinforcement. Psychological Monograph 80, Whole No. 609.

Scarcella, R. \& Oxford, R. (1992). The Tapestry of Language Learning: The Individual in the Communicative Classroom. Boston, MA: Heinle \& Heinle.

Schumann, J. H. (1978). The acculturation model for secondlanguage acquisition. In R. C. Gingras (ed). Second language acquisition and foreign language teaching. Center for Applied Linguistics, Washington, DC, 27-50.

Schumann, J. H. (1986). Research on the acculturation model for second language acquisition. Joumal of Multilingual and Multicultural Development 7(5), 379-392.

Scovel, T. (1978). The effect of affect on foreign language learning: A review of the anxiety research. Language Learning 28, 129-142.

Seliger, H. W. (1983). Learner interaction in the classroom and its effect on language acquisition. In H.W. Seliger \& M.H. Long (eds.), Classroom-Oriented Research in Second Language Acquisition. Rowley, MA: Newbury House. 
Selinker, L. (1972). Interlanguage. International Review of Applied Linguistics 10(3).

Skehan, P. (1989). Individual Differences in Second-Language Learning. London: Edward Arnold.

Slavin, R. (1981). Synthesis of research on cooperative learning. Educational Leadership, 655-660.

Slavin, R. (1983). Cooperative Learning. New York: Longman.

Slavin, R. (Dec.1989-Jan.1990). Research on cooperative learning: Consensus and controversy. Educational Leadership, 52-55.

Slavin, R., Sharan, S., Kagan, S., Hertz-Lazarowitz, R., Webb, C., \& Schmuck, R. (Eds.) (1985). Learning to Cooperate, Cooperating to Learn. New York: Plenum.

Stevick, E. W. (1976). Memory, Meaning, and Method: Some Psychological Perspectives on Language Learning. Rowley, MA: Newbury House.

Tannen, D. (1990). You Just Don't Understand: Men and Women in Conversation. New York: Ballentine.

Tucker, G. R., Hamayan, E., \& Genesee, F. H. (1976). Affective, cognitive, and social factors in second language acquisition. Canadian Modern Language Review 32, 214-226.

Vann, R. \& Abraham, R. (1989). Strategies of unsuccessful language learners. Paper presented at the annual meeting of Teachers of English to Speakers of Other Languages, San Francisco, CA.

Wenden, A. \& Rubin, J. (1987). Learner Strategies in Language Learning. Englewood Cliffs, NJ: Prentice-Hall.

White, R. H. (1959). Motivation reconsidered. Psychology Review 66(5), 297-333.

Wong Fillmore, L.W. (1985). Second language learning in children: A proposed model. Issues in Language Development. National Clearinghouse on Bilingual Education, Rosslyn, VA. 